\title{
ASOCIACIÓN, DISCRIMINACIÓN Y CONSTITUCIÓN: LOS LÍMITES ENTRE LA AUTONOMÍA ASOCIATIVA Y EL DERECHO DE LOS SOCIOS -Y ASPIRANTES A SERLO- A NO SER DISCRIMINADOS
}

DAVID GIMÉNEZ GLUCK 
SUMARIO

1. INTRODUCCIÓN: DELIMITACIÓN DEL OBJETO DE ANÁLISIS. 2. CONCEPTO Y ALCANCE DEL DERECHO DE ASOCIACIÓN EN RELACIÓN CON LA AUTO-ORGANIZACIÓN INTERNA. 3. LÍMITES DEL DERECHO DE AUTOORGANIZACIÓN: EL PRINCIPIO DEMOCRATICO Y LA DIMENSIÓN INTER PRIVATOS. 4. CONCEPTO, ALCANCE Y LÍMITES DEL DERECHO DE NO DISCRIMINACIÓN EN LA RELACIÓN ENTRE PARTICULARES. 5. LOS LÍMITES ENTRE EL DERECHO DE AUTOORGANIZACIÓN Y EL DERECHO DE SOCIOS -Y ASPIRANTES A SERLO-A NO SER DISCRIMINADOS. 6. ÁMBITO DE ACTUACION DEL LEGISLADOR A LA HORA DE REGULAR LA NO DISCRIMINACIÓN COMO LÍMITE DE LA AUTONOMÍA ORGANIZATIVA. 


\title{
ASOCIACIÓN, DISCRIMINACIÓN Y CONSTITUCIÓN: LOS LÍMITES ENTRE LA AUTONOMÍA ASOCIATIVA Y EL DERECHO DE LOS SOCIOS -Y ASPIRANTES A SERLO-A NO SER DISCRIMINADOS*
}

\author{
POR \\ DAVID GIMÉNEZ GLUCK \\ Profesor de Derecho Constitucional \\ Universidad Carlos III
}

\section{INTRODUCCIÓN: DELIMITACIÓN DEL OBJETO DE ANÁLISIS}

En lo que se refiere a la relación entre el derecho de asociación y el derecho a la no discriminación se ha escrito sobre la tensión libertad-igualdad; sobre las relaciones entre los poderes públicos, el individuo y la sociedad; sobre las categorías que podrían constituir un límite a la libre autonomía de la voluntad, y aquellas que no; sobre la posición de dominio de las asociaciones. Sin embargo, todavía quedan ámbitos que no han sido abordados por la doctrina.

El exclusivo objeto de este ensayo es precisamente un aspecto muy específico, y a la vez novedoso, de esta relación. De lo que se trata es de redimensionar

* Este trabajo se ha realizado en el marco del Proyecto de Investigación «Mujer y doble discriminación» (Código DER2009-09947) financiado por el Plan Nacional de I+D del Ministerio de Ciencia e Innovación. 
un conflicto que tradicionalmente se había planteado entre el derecho de asociación (art. $22 \mathrm{CE}$ ) y el derecho a la no discriminación (art. 14 CE) y convertirlo en una relación entre una de las dimensiones del derecho de asociación (el derecho de los socios a organizar la asociación como lo consideren oportuno, lo que se denomina la dimensión auto-organizativa del derecho de asociación) y otra de sus manifestaciones (los derechos inter privatos de los socios frente a la propia asociación) en conexión esta última con el derecho a la no discriminación del art. $14 \mathrm{CE}$. El análisis de los límites de esta relación, y ninguna otra, es la finalidad de este artículo.

\section{CONCEPTO Y ALCANCE DEL DERECHO DE ASOCIACIÓN EN RELACIÓN CON LA AUTO-ORGANIZACIÓN INTERNA}

El derecho de asociación viene reconocido en el art. 22 CE. Debido a que dicho artículo no contiene ninguna definición precisa de este derecho, ha sido el Tribunal Constitucional a través de su jurisprudencia el que ha tenido que definir el alcance y los límites del mismo, así como los contornos de su contenido esencial.

Esta doctrina jurisprudencial ha elaborado un catálogo de manifestaciones del contenido esencial del derecho de asociación que se pueden concretar en las siguientes: «libertad de creación de asociaciones y de adscripción a las ya creadas; libertad de no asociarse y de dejar de pertenecer a las mismas; libertad de organización y funcionamiento internos sin injerencias públicas y, como dimensión inter privatos, garantía de un haz de facultades a los asociados individualmente considerados frente a las asociaciones a las que pertenecen o a las que pretendan incorporarse» ${ }^{1}$.

La facultad de crear y de pertenecer o no a una asociación formaron parte del contenido esencial del derecho de asociación desde la primera jurisprudencia del Alto Tribunal ${ }^{2}$. Pero el derecho de autoorganización y la dimensión inter privatos son aportaciones posteriores, siendo precisamente estas dimensiones las que más nos interesa analizar en este artículo.

El derecho de autoorganización, o autonomía asociativa, forma parte del contenido esencial del derecho de asociación desde la STC 218/1988, donde el

1 Por todas, STC 133/2006, en su F.J.3. Sobre dicha Sentencia, que resuelve una posible afectación de la Ley Orgánica 1/2002, reguladora del derecho de asociación, a las competencias de la Comunidad Autónoma de Cataluña ver ELVIRA PERALES, A.: «A vueltas con el derecho de asociación (Comentario a las Sentencias 133/ y 135/2006, ambas de 27 de abril)» en Revista Española de Derecho Constitucional, 83, Mayo-Agosto 2008, pp. 303-306).

2 Desde la STC 5/81, donde se reconoció la vertiente negativa del derecho de asociación. 
TC afirmó en su FJ1 que el derecho de asociación «comprende no sólo el derecho de asociarse, sino también el de establecer la propia organización del ente creado por el acto asociativo" ${ }^{3}$.

Pero esa facultad de los socios de autoorganizarse no es absoluta. La propia doctrina del Tribunal Constitucional establece que la autonomía asociativa tiene sus límites en la sujeción a la legalidad y al control judicial, aunque matiza que «los Tribunales, como todos los poderes públicos, deben respetar el derecho fundamental de asociación y, en consecuencia, deben respetar el derecho de autoorganización de las asociaciones que, como antes se ha dicho, forma parte del derecho de asociación. Ello supone que las normas aplicables por el Juez eran, en primer término, las contenidas en los Estatutos de la asociación, siempre que no fuesen contrarias a la Constitución y a la ley» ${ }^{4}$.

Por tanto, el derecho de autoorganización abarca el derecho a aprobar los Estatutos de la asociación, con el límite de que deben respetar lo establecido en la Constitución y las leyes, y a los acuerdos libremente adoptados por los órganos de gobierno de la misma, con el límite de que deben respetar los Estatutos de la asociación ${ }^{5}$. Son los Tribunales los que deben decidir si se han respetado estos límites ${ }^{6}$.

Pertenecen, por tanto al derecho de autoorganización todas las decisiones que tienen que ver con las cláusulas estatutarias, entre ellas el procedimiento y las causas de expulsión y la regulación de los procedimientos de incorporación a la asociación, así como los derechos y obligaciones de los asociados en el funcionamiento de la misma y posibles sanciones. También pertenecen a esta ma-

3 Esta jurisprudencia se consolida con otras Sentencias, como las SSTC 185/1993, 96/1994 o $56 / 1995$.

${ }^{4}$ STC 218/1988, F.J.1.

5 Ver VIDAL MARÍN, T.: «El derecho fundamental de asociación y el control judicial de la actividad interna de las asociaciones» en ESPÍN TEMPLADO, E. y DÍAZ REVORIO, F. J.: La Justicia Constitucional en el Estado democrático, Tirant lo Blanch, Valencia, 2000, p. 270.

${ }^{6}$ El debate sobre hasta qué punto pueden los Tribunales controlar los límites del derecho de autoorganización ha sido muy prolijo, sobre todo en lo que tiene que ver con una posible interferencia en la expulsión de los socios. La doctrina mayoritaria entiende que su participación no puede significar entrar a realizar una interpretación de los hechos independiente de la efectuada por los órganos asociativos. Ver, en este sentido, VIDAL MARÍN, T.: «El derecho fundamental de asociación y el control judicial de la actividad interna de las asociaciones» en ESPÍN TEMPLADO E. y DÍAZ REVORIO, F. J.: La Justicia Constitucional en el Estado democrático, op. cit., p. 273. Sin embargo, otros autores otorgan mayor margen de maniobra al juez. Así, MARÍN LÓPEZ matiza que no se puede negar al juez la posibilidad de independizarse del criterio del órgano asociativo, siendo su función fijar los criterios de valoración necesarios para no vulnerar la autonomía asociativa (ver MARÍN LÓPEZ J. J.: «La intervención judicial en los conflictos endoasociativos: el caso de la expulsión de los afiliados» en Poder Judicial, 14, 1989, pp. 158 y ss.). 
nifestación del derecho de asociación todas las decisiones de los órganos de gobierno que se tomen en este sentido. Es por ello por lo que determinados autores, como veremos, han señalado que cualquier requisito discriminatorio en el acceso, expulsión o funcionamiento de la asociación se incluye en esta parte del contenido esencial del derecho de asociación, por lo que cualquier prohibición de los mismos sería inconstitucional. Aquí se va a sostener una posición diferente.

\section{LÍMITES DEL DERECHO DE AUTOORGANIZACIÓN: EL PRINCIPIO DEMOCRÁTICO Y LA DIMENSIÓN INTER PRIVATOS}

Según el Tribunal Constitucional, la Ley y la Constitución son los límites del derecho a la autoorganización. Pero la ley no puede obviamente invadir el contenido esencial de este derecho, pues de hacerlo incurriría en inconstitucionalidad. Por tanto, los límites que establezca la ley a las cláusulas estatutarias han de ser muy respetuosos con la autonomía organizativa de las asociaciones, y deben estar basados en principios constitucionales.

Éste es el caso del principio democrático, que desde 2002 supone un expreso límite legal al principio de autoorganización. Dice el art. 2.5 de la Ley Orgánica 1/2002, de 22 de marzo, reguladora del derecho de asociación (en adelante LODA): «La organización interna y el funcionamiento de las asociaciones deben ser democráticos, con pleno respeto al pluralismo».

Hasta el año 2002, el principio democrático ejercía de límite exclusivamente para un determinado tipo especial de asociaciones - los partidos políticos y los sindicatos- en virtud de los artículos 6 y 7 de la Constitución. Durante este tiempo, algunos autores cuestionaron ampliamente que la imposición legal a las asociaciones de dicho principio fuera compatible con el derecho de asociación en su vertiente autoorganizativa, justificando su existencia constitucional para partidos políticos y sindicatos por las especiales características de estas asociaciones, ligadas de manera especialmente intensa al proceso político y social. Incluso cuando la limitación legal fue un hecho se siguió cuestionando su constitucionalidad, por considerar que el libre ejercicio del derecho de asociación conlleva el derecho de quienes se asocian de organizarse como quieran, incluso antidemocráticamente ${ }^{7}$.

7 DÍEZ-PICAZO GIMÉNEZ, L. M.: Sistema de derechos fundamentales, Civitas, Madrid, 2003, p. 321. FERNÁNDEZ FARRERES considera que sólo una interpretación que conclu- 
Pese a que dicho artículo no ha sido recurrido directamente ante el Tribunal Constitucional, lo cierto es que la STC 135/2006 hace referencia al mismo. En dicha sentencia, el TC considera inconstitucional el requisito de democracia interna contemplado en la Ley del Parlamento de Cataluña 7/1997, de 18 de junio, de Asociaciones. Sin embargo, no lo hace por considerar dicho requisito una intromisión ilegítima en el derecho de autoorganización de las asociaciones, sino por considerar que al no contemplarse en el art. 22 CE sólo el legislador orgánico podrá establecerlo, como excepción a la «libertad de autoorganización que, sin duda (STC 173/1998), se deriva del artículo $22 \mathrm{CE}{ }^{8}$.

En realidad, como señala QUESADA SÁNCHEZ, lo que el legislador orgánico está haciendo es aplicar un principio, como el del principio democrático, que deriva directamente de la Constitución, evitando que exista un compartimento estanco, las asociaciones, donde la CE no llegara a regir, como se derivaría de que en este ámbito pudiera generalizarse la existencia de un funcionamiento interno antidemocrático, que además vulneraría seguramente derechos

ya en que la previsión de la LODA es exclusivamente una exigencia formal sin suponer la imposición de un modelo organizativo sobre otros supondría la posibilidad de considerarla constitucional (FERNÁNDEZ FARRERES, G. y GONZÁLEZ PÉREZ, V.: Derecho de asociación. Comentario a la Ley Orgánica 1/2002, de 22 de marzo, Civitas, Madrid, 2002, p. 131). La misma opinión en BELUCHE RINCÓN, I.: «La autonomía estatutaria y el principio democrático en la organización de las asociaciones» en ABRIL CAMPOY, J. M. y AMAT LLARI, M.E. (coords.): Homenaje al Profesor Lluis Puig i Ferriol, Tirant lo Blanch, Valencia, 2006, pp. 349 y ss. PÉREZ ESCALONA concibe la exigencia de democracia interna como un requisito que supone una restricción injustificada a la libertad de asociación, a la que pertenece la libertad de autoorganización (PÉREZ ESCALONA, S.: La asociación y el Derecho de sociedades: una revisión en clave contractual, Civitas, Madrid, 2007, p. 123). ELVIRA PERALES opina que el art. 2.5 sólo debería aplicarse cuando existe una laguna estatutaria en lo referente a la organización interna de la asociación, pero no se debería imponer como alternativa obligatoria a una asociación que ha decidido darse una autoorganización no democrática (ELVIRA PERALES, A.: «Asociaciones y democracia interna» en ARAGÓN REYES, M.; JIMÉNEZ CAMPO, J. y SOLOZÁBAL ECHAVARRÍA, J. J. (coords.): La democracia constitucional. Estudios en homenaje al Profesor Francisco Rubio Llorente, Congreso de los Diputados, Madrid, 2002, p. 620).

8 Según ELVIRA PERALES, la consideración del art. 2.5 LODA como una excepción a lo señalado en el art. $22 \mathrm{CE}$, cuando éste en realidad está haciendo referencia al régimen general de las asociaciones, puede hacer pensar que el TC está declarando implícitamente la inconstitucionalidad de dicho precepto (ELVIRA PERALES, A.: "A vueltas con el derecho de asociación (Comentario a las Sentencias 133 y 135/2006, ambas de 27 de abril)» en Revista Española de Derecho Constitucional, op. cit., p. 319). Sin embargo, en mi opinión, y aceptando que sólo una cuestión de constitucionalidad puede despejar este dilema, el TC en esta sentencia no está más que explicando por qué el legislador orgánico ha podido regular la democracia interna, posibilidad que niega al legislador autonómico. 
fundamentales de los socios al negarles el derecho a participar democráticamente de los asuntos internos de la asociación?.

En efecto. Una supuesta vulneración del principio democrático supondría a su vez una vulneración de determinados derechos individuales de los socios, protegidos también como parte integrante del contenido esencial del derecho de asociación. A este conjunto de derechos de los socios frente a su propia entidad asociativa se le conoce como la dimensión inter privatos del derecho de asociación, y su debido respeto como parte del contenido esencial del art. 22 $\mathrm{CE}$ se reconoce por primera vez en nuestra jurisprudencia constitucional a través de la STC 173/1998. Concretamente, el FJ 8 de dicha Sentencia define esta dimensión como la garantía de «un haz de facultades a los asociados considerados individualmente frente a las asociaciones a las que pertenecen, $\mathrm{o}$, en su caso, a los particulares respecto a las asociaciones a las que pretenden incorporarse» ${ }^{10}$.

La propia LODA, en su artículo 21, enumera cuáles son esos derechos, que habría que dividir entre los derechos dirigidos a la participación en los asuntos de la asociación, como el derecho al voto, el derecho a asistir a la Asamblea General, a ser informado de la composición de los órganos de gobierno, del estado de las cuentas, y los derechos encaminados a garantizar un proceso disciplinario justo con la posición de los socios, como el derecho a ser oído con carácter previo a la adopción de una medida disciplinaria contra él —sanción, suspensión, expulsión-, el derecho a ser informado de los hechos, y a una motivación en el acuerdo de sanción, así como el derecho a impugnar dicho acuerdo, si lo considera contrario a los Estatutos o la Ley.

Pero la dimensión inter privatos del derecho de asociación no sólo afecta a los que ya son socios. Como muy acertadamente señala MARTÍN HUERTAS, el TC dice que hay que incluir dentro de este ámbito también el derecho de aquellos que todavía no son socios a no ser impedida su afiliación por motivos

9 QUESADA SÁNCHEZ, A. J.: «Democracia interna y asociaciones: reflexiones desde una óptica civil» en Diario la Ley, n. 7062, 24 Nov. 2008. Tampoco AGUIAR DE LUQUE considera inconstitucionales determinadas limitaciones a la libertad de autoorganización basadas en el art. 9.2 CE (AGUIAR DE LUQUE, L., y ELVIRA PERALES, A.: "Artículo 22․ El derecho de asociación» en ALZAGA VILLAAMIL, O.: Comentarios a la Constitución Española de 1978, Título II, Edersa, Madrid, 1997, pp. 622-623).

${ }^{10}$ Como apunta GALLARDO MOYA, es evidente que la garantía de dichas facultades son un medio para garantizar el carácter democrático de la asociación (GALLARDO MOYA, V.: "Derecho de asociación y exigencia de democracia interna de los partidos políticos (Comentario a la STC 56/1995, de 6 de marzo)» en Derecho Privado y Constitución, 8, 1996, p. 245). 
arbitrarios o faltos de razonabilidad ${ }^{11}$. Por tanto, también es desarrollo del contenido esencial del derecho de asociación el derecho a asociarse, es decir, el derecho a no ser impedida la afiliación por motivos arbitrarios o faltos de razonabilidad y, por tanto, negativamente discriminatorios.

Esta posición tiene todo su sentido. Si todas las asociaciones de un sector, en el ejercicio de su facultad autoorganizativa, utilizaran un criterio arbitrario, injustificado, absurdo, como el color de la piel, para realizar su proceso de admisión, dicha práctica podría llevar a la situación de que una persona con un color de piel distinto del requerido no tuviera acceso al derecho de asociación, salvo que encontrara alguien con el que poder asociarse para fundar una nueva asociación en la que no se exigiera dicho requisito absurdo. Parece del todo punto razonable que el ejercicio del derecho de asociación de esta persona no se condicione al cumplimiento de esta condición; parece lógico considerar que el contenido esencial de su derecho de asociación incluya el derecho a no ser rechazado en asociaciones ya constituidas por motivos arbitrarios e injustificados.

Todos estos derechos de los socios - y de los que quieren serlo- condicionan de alguna manera una estructura organizativa determinada, por lo que se puede concluir que limitan la facultad autoorganizativa de la asociación. Pero esa limitación es aceptable desde el momento en que se realiza para salvaguardar un ámbito de derechos que también pertenece al ámbito del contenido esencial del derecho de asociación. Esta tensión entre los derechos de los socios frente a la asociación y el derecho de los socios a la autoorganización de su propia asociación se aprecia principalmente en la aplicación del régimen disciplinario, siendo el Poder Judicial el encargado de decidir cuál de los derechos ha de prevalecer. En lo relativo a la expulsión de un socio, el TC señala que dicho control judicial debe limitar su intervención a comprobar la competencia del órgano asociativo actuante, la regularidad del procedimiento seguido y si, de hecho, existieron o no las circunstancias que puedan servir de fundamento a la decisión de los socios, dejando la decisión sobre esas circunstancias al arbitrio de los órganos directivos de la asociación ${ }^{12}$. ¿De esta jurisprudencia se desprende que sería posible que una persona fuera expulsada de la asociación si incurre en una causa de expulsión absurda, arbitraria e injustificada — siguiendo con el ejemplo anterior, porque el color de su piel se torne negro-, si ésta viene contemplada en los Estatutos y los

${ }^{11}$ MARTÍN HUERTAS, A.: El contenido esencial del derecho de asociación, Congreso de los Diputados, Madrid, 2009, p. 367. El Tribunal Constitucional, como hemos visto antes, señala expresamente en su STC 173/1998 (FJ8) que la dimensión inter privatos del derecho de asociación abarca a «los particulares frente a las asociciones a las que pretenden incorporarse».

12 STC 104/1999, FJ3. 
mismos han sido aplicados por el órgano asociativo competente siguiendo el procedimiento debido? En este artículo se defiende una respuesta negativa, porque los Estatutos han de estar sometidos a la Constitución y a la Ley ${ }^{13}$, y en este sentido, en las causas y procedimientos de expulsión de los asociados, se han de respetar el conjunto de derechos fundamentales presentes en la Carta Mag$\mathrm{na}^{14}$. Por tanto, los órganos directivos de la asociación no pueden expulsar a un socio por una causa absurda que no esté en los Estatutos, pues ello vulneraría el ámbito inter privatos de sus derechos como socio, y tampoco podría serlo si viene contemplada dicha causa arbitraria en los Estatutos, pues unos Estatutos con este tipo de cláusulas no tendrían cabida en nuestro ordenamiento jurídico.

La pregunta que cabe hacerse a esta altura del ensayo es en qué consistirían estas causas arbitrarias, injustificadas que vulnerarían los derechos inter privatos de los socios frente a la asociación y qué causas de no admisión o expulsión entran dentro de las facultades autoorganizativas del derecho de asociación que legítimamente ejercen los socios de una entidad asociativa. Nosotros pensamos, como hemos dicho, que el color de la piel — la raza — es sin duda una causa arbitraria de exclusión o expulsión de un socio, al igual que ocurre con el género, la orientación sexual o la discapacidad, entre otros motivos discriminatorios. Para justificar esta conclusión deberemos repasar primero la diferencia entre cláusula general de igualdad y principio de no discriminación y la incidencia que este último tiene en las relaciones entre particulares.

\section{CONCEPTO, ALCANCE Y LÍMITES DEL DERECHO DE NO DISCRIMINACIÓN EN LA RELACIÓN ENTRE PARTICULARES}

El art. 14 CE establece el siguiente principio: «Los españoles son iguales ante la ley, sin que pueda prevalecer discriminación alguna por razón de nacimiento, raza, sexo, religión, opinión o cualquier otra condición o circunstancia personal o social». Con este artículo, la igualdad se convierte, además de en un valor superior del ordenamiento jurídico (art. 1.1 CE), en un derecho fundamental alegable directamente ante los Tribunales.

${ }^{13}$ Así lo ratifica el art. 7.3 de la LODA: «El contenido de los Estatutos no podrá ser contrario al ordenamiento jurídico».

${ }^{14}$ Así lo apunta, y coincido con él, MARÍN LÓPEZ, J. J.: «Derecho fundamental de asociación: aplicación a las cooperativas. Expulsión de asociado; control sobre las causas de expulsión; ámbito de intervención judicial (Comentario a la Sentencia del Tribunal Constitucional 96/1994, de 21 de marzo)» en Cuadernos Civitas de Jurisprudencia Civil, 35, 1994, p. 781. 
Pero desde el primer momento, la jurisprudencia del Tribunal Constitucional tuvo muy claro que el artículo 14 no significaba la prohibición de cualquier norma que estableciera alguna diferencia entre sus distintos destinatarios. La norma jurídica, la ley, ya sea penal, administrativa, civil, laboral, se caracteriza precisamente por diferenciar entre distintos ciudadanos, aplicando consecuencias jurídicas diferentes a unos y a otros. La Constitución no estableció el principio de igualdad para prohibir cualquier tipo de diferenciación en la norma, pues eso sería ir en contra de la misma esencia del Derecho.

Lo que realmente pretende el art. $14 \mathrm{CE}$, y así lo interpretó el TC desde su más pronta jurisprudencia, es la interdicción de aquellas diferenciaciones que no son objetivas, razonables ni proporcionadas ${ }^{15}$. Y para decidir cuándo estamos ante una diferenciación aceptable o ante una irrazonable o desproporcionada el TC aplica el juicio de igualdad: si supera dicho juicio la diferenciación es constitucional y si no lo hace la diferenciación es inconstitucional, y la conoceremos como discriminación ${ }^{16}$.

Pero la intensidad con la que se aplica dicho juicio varía en función de que estemos ante un supuesto u otro. En general, la intensidad del juicio es muy leve — juicio de mínimos-, como si el TC fuera consciente de que debe autorestringirse de manera especialmente acusada en un supuesto como éste, en el que la genérica presunción a favor de la constitucionalidad de la acción del legislador se ve agravada por el hecho de que la posible inconstitucionalidad no se basaría en la dicción literal de la norma constitucional, sino en una construcción jurisprudencial —el juicio de igualdad— diseñado por el Alto Tribunal a raíz de dicha norma, con un sesgo marcadamente subjetivo que ni al propio TC se le escapa. Éste es el tipo de juicio —el juicio de mínimos— que la jurisprudencia

15 En esta jurisprudencia se impone la obligación de dispensar el mismo trato a quienes se encuentran en situaciones jurídicas equiparables, con prohibición de toda discriminación o desigualdad de trato que, desde el punto de vista de la finalidad de la norma cuestionada, carezca de justificación objetiva y razonable. Ver, por todas, las SSTC 180/1985m 113/1984 y 117/1988.

${ }^{16}$ El juicio de igualdad se estructura en dos subjuicios: el juicio de racionalidad y el juicio de proporcionalidad. Ambos subjuicios han de ser superados para considerar constitucional una norma. El subjuicio de racionalidad consiste en determinar si la clasificación legislativa aplica un trato diferente a grupos de sujetos similares o disimilares. Sólo si las categorías en que la ley divide a la sociedad son supuestos de hecho diferentes respecto a la finalidad de la norma aquella puede considerarse racional. El subjuicio de proporcionalidad se resume en la necesidad de que exista una relación proporcionada entre la finalidad de la diferencia de trato y la limitación de derechos e intereses individuales que dicha diferenciación produce en los ciudadanos que constituyen la categoría a la que se trata desfavorablemente. Un análisis sobre la estructura del juicio de igualdad en GIMÉNEZ GLUCK, D.: Juicio de igualdad y Tribunal Constitucional, Ed. Bosch, Barcelona, 2004, pp. 55-121. 
constitucional aplica a lo que se denomina la cláusula general de igualdad: «Los españoles son iguales ante la ley..». Dicha cláusula cubre toda diferenciación en la norma que clasifique entre ciudadanos o grupos sociales, lo que se denominan clasificaciones socioeconómicas.

Sin embargo, el art. 14 CE dice algo más. Después de establecer la cláusula genérica, señala: «....sin que pueda prevalecer discriminación alguna por razón de nacimiento, raza, sexo, religión, opinión o cualquier otra condición o circunstancia personal o social». A estas concreciones, la doctrina las ha denominado cláusulas específicas de no discriminación ${ }^{17}$. El TC no es tan permisivo con las normas que distinguen en función de estos «rasgos sospechosos». El juicio de igualdad se vuelve más intenso: es lo que se conoce como juicio estricto. Lo que el TC interpreta es que el Poder Constituyente decidió con estas cláusulas advertir a los operadores jurídicos de que las diferenciaciones contra determinados colectivos históricamente estigmatizados, como las minorías étnicas, las mujeres, o las minorías religiosas, no podían someterse a juicio de mínimos, pues del trato histórico que éstos habían recibido, y de su actual situación sociológica, no cabía depositar confianza alguna en que el legislador fuera a tratarlos con ecuanimidad. Decidió desconfiar de los poderes públicos en el trato que ofrecen a estos grupos tradicionalmente discriminados por su sexo, raza, etc., encomiando al TC —o al menos así lo interpretó él— a efectuar juicio estricto a aquellas diferenciaciones que trataran desfavorablemente a aquellos colectivos, lo que significaba la declaración de inconstitucionalidad salvo que la norma justificara de forma meridiana la razonabilidad y proporcionalidad de la medida.

Esta distinción entre cláusula general de igualdad y cláusulas específicas de no discriminación se proyecta, a su vez, sobre las relaciones entre los particulares, hasta el punto de que la primera no se aplica a las mismas y las segundas sí. Así lo señala el Tribunal Constitucional: «(...)el respeto de la igualdad ante la ley se impone a los órganos del poder público, pero no a los sujetos privados, cuya autonomía está limitada sólo por la prohibición de incurrir en discriminaciones

${ }^{17}$ La distinción entre cláusula general de igualdad y cláusulas específicas de no discriminación fue por primera vez expuesta en RODRÍGUEZ-PIÑERO, M. y FERNÁNDEZ LÓPEZ, M. F: Igualdad y discriminación, Tecnos, Madrid, 1986, pp. 172-173. En este sentido, hay que resolver el significado de la cláusula abierta del art. $14 \mathrm{CE}$ in fine: "cualquier condición o circunstancia personal o social». Dicha cláusula tiene realmente como finalidad que determinados rasgos especialmente odiosos no recogidos expresamente en el art. $14 \mathrm{CE}$ puedan ser incorporados a este elenco a través de la jurisprudencia del Tribunal Constitucional, como ocurrió, por ejemplo, con la discapacidad en la STC 269/1994. Para ampliar este argumento ver GIMÉNEZ GLUCK, D.: Juicio de igualdad y Tribunal Constitucional... op. cit., pp. 229-265. 
contrarias al orden público constitucional, como son entre otras las que expresamente se indican en el artículo 14 CE» (STC 108/1989).

$\mathrm{Al}$ mismo tiempo, el propio TC advierte que el alcance que las cláusulas específicas de no discriminación tiene entre los particulares es distinto del que tiene respecto a los poderes públicos. Como apunta la STC 177/1988, en el primero de los casos, el principio de igualdad ha de hacerse compatible con otros valores que tienen su origen en el principio de la autonomía de la voluntad. Ello significa que el juicio de constitucionalidad de la diferencia de trato ha de ser necesariamente diferente; existe un distinto trato constitucional entre la que procede de un organismo público o de una ley y la que tiene su origen en un particular, sea éste un empresario o una asociación. El margen de actuación de este último en el trato desigual es mucho mayor ${ }^{18}$.

Pero que exista un margen de actuación mayor no significa que este margen sea ilimitado. En realidad, como señala BILBAO UBILLOS, en estos supuestos el órgano judicial, a la hora de enjuiciar la constitucionalidad de una medida basada en alguno de los rasgos expresamente recogidos en el art. 14, habrá de realizar una ponderación entre el principio de no discriminación y la autonomía privada de la voluntad, ponderación que se habrá de basar en tres factores principales: la repercusión social de la discriminación; la posición dominante o monopolística de la entidad discriminadora en el mercado o la sociedad; y la afectación al núcleo esencial de la dignidad o integridad moral de la persona discriminada ${ }^{19}$.

Y todo ello sin necesidad de que medie una previa intervención del legislador para concretar el alcance del principio de no discriminación en el ámbito concreto de las relaciones entre particulares que se esté analizando. Es decir, el art. $14 \mathrm{CE}$ se puede alegar directamente ante los Tribunales frente a cualquier violación del mismo en las relaciones privadas, y en ese momento el órgano judicial deberá realizar la ponderación anteriormente expuesta entre dicho principio y la autonomía de la voluntad.

Esta aplicación directa no ha sido impedimento para que el legislador haya considerado mejor intervenir en determinados ámbitos, concretando dicha prohibición. En este caso, lógicamente, el principio de no discriminación sale reforzado respecto al de autonomía de la voluntad.

18 Sobre cómo la autonomía de la voluntad limita, pero no anula, la eficacia de los derechos fundamentales ver LÓPEZ AGUILAR, J. F.: Derechos fundamentales y libertad negocial (sobre el espacio constitucional para la autonomía de la voluntad entre particulares), Ministerio de Justicia, Madrid, 1990 y BILBAO UBILLOS, J. M.: La eficacia de los derechos fundamentales frente a los particulares (análisis de la jurisprudencia del Tribunal Constitucional), CEPC, Madrid, 1997.

19 BILBAO UBILLOS, J. M.: «Prohibición de discriminación y relaciones entre particulares» en Teoría y Realidad Constitucional, 18, 2006, pp. 155-157. 
Es el supuesto, por ejemplo, de la legislación laboral antidiscriminatoria, cuyo precepto más significativo es el art. 17.1 del Real Decreto Legislativo 1/1995, de 24 de marzo, por el que se aprueba el Texto Refundido de la Ley del Estatuto de los Trabajadores ${ }^{20}$ : «Se entenderán nulos y sin efecto los preceptos reglamentarios, las cláusulas de los convenios colectivos, los pactos individuales y las decisiones unilaterales del empresario que contengan discriminaciones directas o indirectas desfavorables por razón de edad o discapacidad o favorables o adversas en el empleo, así como en materia de retribuciones, jornada y demás condiciones de trabajo por circunstancias de sexo, origen, incluido el racial o étnico, estado civil, condición social, religión o convicciones, ideas políticas, orientación sexual, adhesión o no a sindicatos y a sus acuerdos, vínculos de parentesco con otros trabajadores en la empresa y lengua dentro del Estado español».

Pese a que el acceso, promoción y trato en el empleo, por la importancia que supone para el desarrollo vital de una persona, se ha constituido como la actividad donde las leyes antidiscriminatorias han centrado la mayor parte de su esfuerzo, existen otros diversos ámbitos circunscritos a las relaciones privadas donde también se ha legislado contra conductas discriminatorias, como, por ejemplo, en el acceso a bienes y servicios, como pólizas de seguro, o la falta de accesibilidad a los edificios ${ }^{21}$.

Una vez asumido en qué consiste en derecho a la no discriminación entre particulares, la pregunta que debemos hacernos es doble. En primer lugar, debemos preguntarnos si una conducta discriminatoria procedente de una asociación puede ser impugnada directamente ante los Tribunales por vulnerar el art. 14 CE. Debemos considerar si el principio de la autonomía de la voluntad, en

${ }^{20}$ En su redacción dada por la Ley Orgánica 3/2007 de 22 de marzo.

21 Estas prohibiciones legales se centran especialmente en tratamientos discriminatorios procedentes del ámbito privado contra mujeres o personas con discapacidad, los dos colectivos con una legislación antidiscriminatoria más avanzada. Por ejemplo, el art. 69 de la Ley Orgánica 3/2007 de 22 de marzo, para la igualdad efectiva de mujeres y hombres señala lo siguiente: «Todas las personas físicas o jurídicas que, en el sector público o en el privado, suministren bienes o servicios disponibles para el público, ofrecidos fuera del ámbito de la vida privada y familiar, estarán obligadas, en sus actividades y en las transacciones consiguientes, al cumplimiento del principio de igualdad de trato entre mujeres y hombres, evitando discriminaciones, directas o indirectas, por razón de sexo.». En el ámbito de las personas con discapacidad, la Ley 51/2003, de 2 de diciembre, de igualdad de oportunidades, no discriminación y accesibilidad universal de las personas con discapacidad, en su artículo 9, señala la obligación de los poderes públicos de establecer unas condiciones básicas de accesibilidad que estimulen la adopción de normas internas en las empresas o centros que promuevan la eliminación de las barreras arquitectónicas o tecnológicas que suponen una discriminación para las personas con discapacidad. 
coordinación con el derecho a la autoorganización de dicha asociación, permite o no utilizar los rasgos sospechosos arbitrariamente. Debemos estudiar cómo se debería producir esa ponderación de valores, y qué decisión parece la más conforme a la Constitución.

En segundo lugar, en plena conexión con la primera pregunta, debemos plantearnos si es constitucionalmente aceptable una reforma legislativa que concretara el principio antidiscriminatorio en el ámbito asociativo, de la misma manera que ya se ha hecho en el ámbito laboral, o en relación con el suministro de bienes y servicios. Es decir, una reforma legislativa que prohibiera todo tipo de utilización arbitraria de los rasgos sospechosos en el acceso y funcionamiento de las asociaciones, o que prohibiera expresamente alguna de estas prácticas, las más graves, como la denegación de la condición de socio o la expulsión de la asociación por compartir alguno de los rasgos recogidos expresamente el art. $14 \mathrm{CE}$. Debemos plantearnos, por fin, si esta plasmación legal facilitaría o no la aplicación del principio antidiscriminatorio al funcionamiento de las asociaciones.

\section{LOS LÍMITES ENTRE EL DERECHO DE AUTOORGANIZACIÓN Y EL DERECHO DE SOCIOS - Y ASPIRANTES A SERLO-A NO SER DISCRIMINADOS}

Hay una buena parte de la doctrina que piensa que la autonomía asociativa para organizarse ejerciendo la autonomía de su voluntad es un límite infranqueable, en todo tipo de situaciones, para el derecho a la no discriminación. Algunos, como PACE, afrontan esta controversia como una manifestación más del conflicto entre la libertad y la igualdad, concluyendo que en el caso que nos ocupa no se puede imponer a las asociaciones la obligación de no discriminar por razón de género - es éste el ejemplo que utiliza, aunque es aplicable a cualquier otro tipo de discriminación-. Para este autor, algo así sería «introducir la coacción en las dinámicas asociativas internas». Este conflicto, según el autor, nos confirma lo difícil que resulta compatibilizar la igualdad y la libertad a través de la intransigencia jurídica, y se muestra partidario de alcanzar la igualdad en las asociaciones a través del progreso cultural y social ${ }^{22}$.

Otros piensan que el derecho a la no discriminación sólo podrá limitar el derecho de autoorganización de las asociaciones en aquellos casos en los que dichas

22 PACE, A.: «Igualdad y libertad» en Revista Española de Derecho Constitucional, 64, EneroAbril 2002, pp. 74-77. 
asociaciones se encuentran en una posición de dominio. Esta doctrina hunde sus raíces en el Derecho alemán, y consiste en distinguir entre aquellas asociaciones que tienen una finalidad lúdica o recreativa, sin otra pretensión que el esparcimiento y ocio de sus miembros en alguna afición o pasatiempo, y aquellas asociaciones cuya pertenencia a las mismas incide directamente en la igualdad de oportunidades a la hora de acceder a bienes y servicios, o disfrutar de ciertas ventajas económicas, porque las mismas se encuentran en una posición de dominio en un sector económico o social determinado. Mientras las primeras no gozarían de límite alguno en su capacidad de discriminar, en aras de la libertad de asociación, las segundas se verían constreñidas, no por el hecho en sí de la discriminación en el seno de la asociación, sino por las consecuencias ulteriores que esta actitud podría tener sobre las oportunidades económicas y sociales de las personas discriminadas ${ }^{23}$.

Esta posición encuentra cierto apoyo en España en la STC 218/1988, que distingue, a la hora de decidir si la apreciación judicial se debe limitar a verificar si se han dado las circunstancias que puedan servir de base a la decisión de los socios de expulsar a otro, entre asociaciones puramente privadas y otra que «ostentase de hecho o de Derecho una posición dominante en el campo económico, cultural, social o profesional de manera que la pertenencia o exclusión de ella supusiese un perjuicio significativo para el particular afectado...» (FJ3). Y ya circunscribiéndonos al conflicto con el derecho a la no discriminación, se plasma también en la Sentencia del Tribunal Supremo de 8 de febrero de 2001, y el posterior Auto del Tribunal Constitucional 254/2001 que desestimó la admisión a trámite del recurso de amparo de la Cofradía de El Palmar (Valencia) en su in-

${ }^{23}$ Ésta es la posición por la que parece inclinarse BILBAO UBILLOS en BILBAO UBILLOS, J. M.: «Prohibición de discriminación y relaciones entre particulares»... op. cit., pp. 183-188. Como explican SALVADOR CODERCH y FERRER I RIBA esta construcción doctrinal es la predominante en la jurisprudencia y doctrina alemana. Concretamente, los alemanes señalan que el derecho a ingresar en una asociación sólo es evidente si lo señala la ley. Si no es así, en un principio la jurisprudencia aplicó el test de la posición monopolística, según el cual una asociación que detente una posición de monopolio en un sector de actividad no podría negarse a admitir a un miembro por motivos discriminatorios, pasando posteriormente a aplicar el test más amplio de la posición de predominio en la función económica o social, que impide el trato discriminatorio a aquellas asociaciones que ocupan posiciones de poder social, económico o político. El resto de las asociaciones, salvo norma legal en contrario, estarían habilitadas para utilizar los criterios que consideren oportunos a la hora de admitir un nuevo socio, aunque éstos fueran discriminatorios (SALVADOR CODERCH, P. y FERRER I RIBA, J.: "Asociaciones, democracia y Drittwirkung” en Asociaciones, derechos fundamentales y autonomia privada, Civitas, Madrid, 1997, pp. 103-109). Ver también PÉREZ ESCALONA, S.: El derecho de asociación y las asociaciones en el sistema constitucional español, Thomson, Madrid, 2007, p. 94. 
tento de excluir a las mujeres de la misma. El Auto lo dice de manera muy nítida: «...No puede ampararse en la autonomía de la voluntad de las asociaciones privadas una decisión como la enjuiciada en las Sentencias recurridas en amparo, consistente en denegar u obstaculizar el ingreso a la Comunidad de Pescadores por razón de sexo, cuando esta comunidad ocupa una posición privilegiada, al tener reconocida por el Poder público la explotación económica en exclusiva de un dominio público, las aguas de la Albufera y su riqueza piscíscola» (FJ4). En efecto, la denegación del amparo se basa en que la discriminación había tenido consecuencias económicas sobre las mujeres discriminadas, que se habían visto privadas de ejercer la actividad pesquera en la Albufera por la posición de dominio de la asociación discriminadora.

En Estados Unidos se ha desarrollado otro punto de vista alternativo en la ponderación entre el derecho a la no discriminación y la autonomía asociativa, consistente en admitir que, como regla general, el derecho a la no discriminación pueda limitar el derecho de autoorganización de las asociaciones, salvo en aquellos supuestos en los que la asociación haya sido creada con el objetivo de defender en la sociedad una determinada posición política, ideológica o social que se constituye como garantía instrumental de la libertad de expresión, posición que quedaría dañada por la condición de la determinada persona que se quiere expulsar o no admitir (expressive association) ${ }^{24} \mathrm{y}$ en los que la asociación se haya constituido para compartir aspectos íntimos de la vida de un número reducido de personas (intimate association). En el resto de los supuestos, el principio de no discriminación se impone sobre la autonomía asociativa.

A nivel federal, el Título II de la Ley de Derechos Civiles de 1964 establece la prohibición de utilizar la raza, el color, la religión o el origen nacional para segregar en cualquier establecimiento, como restaurantes, hoteles, moteles, etc.. abiertos, de hecho, al público. Estas previsiones no se extienden a clubes privados no abiertos al público ni a asociaciones. Por tanto, estar abierto al público (public acommodation) es la clave para considerar que un club, una asociación, un establecimiento, deba o no permitir la entrada de minorías raciales en sus dependencias ${ }^{25}$. En todo caso, la relación de public accommodations se ha extendi-

${ }^{24}$ Por ejemplo, que una asociación religiosa deba admitir a un ateo, o una asociación feminista a un hombre machista.

${ }^{25}$ Esta fijación por la exposición al público parte del hecho de que la conducta racista que se quería combatir tenía en los Estados del Sur su plasmación más odiosa en la segregación de los negros de una gran parte de los establecimientos públicos, como restaurantes, salas de baile, tiendas, etc...Esta política de segregación fue practicada en los Estados del Sur desde la abolición de la esclavitud, no sólo por personas privadas, objeto de la Civil Rights Act, sino también por los propios poderes públicos. Fue inicialmente convalidada por el Tribunal Supremo de los Estados Unidos en 
do mucho, abarcando casi a 50 tipos de establecimientos, incluso a clubes como el Rotary o los boys scouts.

Ninguna ley federal, sin embargo, prohíbe la discriminación en las asociaciones. Sin embargo, a nivel estatal y local, algunas ciudades y Estados en los años 80 exigieron la admisión de mujeres en clubes privados orientados a los negocios. En repetidas ocasiones, el Tribunal Supremo dictaminó que estas leyes no atentaban contra la Primera Enmienda que protege el derecho de asociación, ya que la aplicación de esta prohibición no interfería con las ideas que la organización buscaba expresar: no eran expressive associations. En estas condiciones, un compelling interest del Estado, como prohibir la discriminación, podía imponerse a la Primera Enmienda ${ }^{26}$. Por otro lado, en 2000 el mismo Tribunal Supremo senaló que el derecho de asociación de la Primera Enmienda impedía al Estado de New Yersey obligar a los Boys Scouts a aceptar un homosexual entre sus monitores, pues ello iba en contra de los principios de dicha asociación, entre los cuales se encuentra el de no promover públicamente la homosexualidad como una conducta apropiada, por considerarla sucia e inmoral ${ }^{27}$. Por tanto, en Estados Unidos el principio de no discriminación puede constituirse como límite de la autonomía asociativa, salvo cuando los fines sociales, políticos o ideológicos de la asociación sean incompatibles con la imposición de dicho principio.

Volvamos a España. Es una evidencia que casi siempre se ha enfocado esta controversia como una ponderación de derechos, de valores, —la libertad de asociación vs. la igualdad-. De lo que se trata es, al parecer, de encontrar dónde está el límite en el que comienza uno y acaba otro. Pongamos el ejemplo de la posición de dominio, que aunque nuestra jurisprudencia constitucional todavía no ha entrado de lleno en la materia, parece ser la más aceptada: lo que se nos está diciendo es que en la ponderación de derechos ha de predominar la libertad de asociación, salvo que el ejercicio de este derecho se realice por una asociación que suponga un medio ineludible para alcanzar bienes sociales o económicos determinados, en cuyo caso la libertad de asociación debe ceder al derecho a la no discriminación. ¿¿Por qué? Porque se piensa que en circunstancias

su Setencia Plessy vs. Ferguson, 163 US 537 (1896), que concluyó que la segregación racial era constitucional pues separar no era sinónimo de de discriminar. Ya en la década de los 50, las Setencias Brown vs. Board of Education of Topeka, 347 US 483 (1954) y Bolling vs. Sharpe, 347 US 497 (1954), rebatieron esta interpretación, declarando inconstitucional la segregación racial procedente de los poderes públicos estatales y federales, respectivamente.

${ }^{26}$ Esta doctrina se consolida en las Setencias Board of Directors of Rotary Int'l vs. Rotary Club of Duarte, 481 US 537 (1987); Roberts v. United States Jaycees, 468 US 622(1984); New Cork State Club Assn.,Inc v. City of New Cork, 487 US 1 (1988).

27 Boy Scouts of America vs. Dale 530 US 640 (2000). 
normales las personas excluidas podrían formar asociaciones alternativas con las que cumplir los fines que buscaban con la adhesión a la que les rechaza, y ello atenúa la discriminación. Pero si esa alternativa no es real, por la posición de dominio de esta última, la discriminación se torna ineludible.

Algunos han echado mano de la posición de dominio para circunscribir la limitación del derecho a la no discriminación a aquellas asociaciones que suponen una dimensión económica para sus socios ${ }^{28}$. Pero no siempre la posición de dominio se debería traducir exclusivamente en beneficios económicos para los socios: también debería tenerse en cuenta la posición de dominio en la dimensión social. ¿¿Sería la exclusión de las mujeres de las cofradías festeras tradicionales de un pueblo algo admisible, siguiendo el criterio de la posición de dominio? Se podría decir que siempre tendrían la oportunidad de montar otra, que no excluyera a mujeres. Y no se ven perjudicadas económicamente por la no pertenencia a la misma. Pero también se podría decir que estas asociaciones tienen una posición de dominio en su ámbito social (reconocimiento social en la localidad como organizadoras de festejos), lo que debería limitar su autonomía asociativa $^{29}$.

${ }^{28}$ Concretamente, BILBAO distingue entre la asociación que ejerce una actividad en régimen de monopolio u oligopolio, es decir, en posición de dominio, y la que tiene una finalidad lúdica o recreativa, señalando que el legislador no puede prohibir la discriminación en las últimas, pues ello tendría un coste muy alto en términos de libertad (BILBAO UBILLOS, J. M.: «Prohibición de discriminación y relaciones entre particulares» en Teoría y Realidad Constitucional, 18... op. cit., pp. 186-187).

${ }^{29}$ Hay determinados acontecimientos tradicionales en los pueblos de España que son claves para comprender la idiosincrasia de los mismos. Algunos de ellos son manifestaciones religiosas o paganas que se celebran en la calle y que, por la tradición, se han convertido en lo más esperado del año. Estar, participar en los mismos es signo de integración en la localidad, de prestigio social. Normalmente los organizan asociaciones, como cofradías, clavarios, quintos, etc.. con apoyo público del Ayuntamiento.

Cuando estas personas salen a la calle no están haciendo otra cosa que ejercer su derecho de reunión y manifestación. En algunas de ellas, no se permite la participación de mujeres. ¿Es esta discriminación perseguible? Ya se ha intentado. Nos estamos refiriendo al caso del ALARDE de Irún y de Hondarribia, en Guipúzcoa. Se trata de una fiesta popular en la que se conmemora los hechos de armas del 7 de septiembre de 1638 y el 30 de junio de 1552, respectivamente, cuando los defensores de Hondarribia e Irún consiguieron levantar el sitio al que le habían sometido tropas francesas. Desfilan hombres uniformados en compañías y escuadrones, con las mujeres sólo como cantineras. Un par de asociaciones de mujeres intentaron incorporarse al Alarde en 1998, produciéndose incidentes. La Ertzaintza, al poner orden, evitó que la Compañía de mujeres se incorporara.

La Justicia (SSTS de 19 de septiembre de 2002) respondió, en principio, dando la razón a las mujeres, pues eran actos organizados por los Ayuntamientos. Pero, posteriormente, cuando la organización corrió a cargo de una entidad privada, se convalidó su constitucionalidad (STS de abril 
En realidad, enfocar el debate como una confrontación entre la libertad de asociación y el derecho a la no discriminación es simplificar excesivamente la cuestión. Se trata de un asunto algo más complejo. Por supuesto que hay que ponderar entre el derecho a la no discriminación y la libertad de asociación en su vertiente de derecho a la autoorganización, es decir, el derecho de los socios a organizar libremente su propia asociación. Pero además de ello, en mi opinión, también hay que tener en cuenta que el contenido esencial del derecho de asociación, como ya hemos visto, no sólo abarca el derecho a la auto-organización, sino también lo que denominamos la dimensión inter privatos, es decir, el haz de derechos que los socios y los que aspiran a serlo tienen frente a la propia asociación y que limita que éstos puedan ser tratados arbitrariamente sin posibilidad de defenderse, lo que se traduce principalmente en limitaciones en cómo las asociaciones pueden admitir o expulsar a sus socios.

Esta dimensión inter privatos, como el principio democrático, suponen lógicamente un límite para el derecho de autoorganización de la asociación. Por tanto, la tensión no se debería plantear entre el derecho de asociación y el derecho a la no discriminación, sino entre la dimensión autoorganizativa del derecho de asociación y la dimensión inter privatos del mismo traducido en el derecho de los socios y los aspirantes a serlo a no ser discriminados por razones absurdas y arbitrarias, como por ejemplo el color de su piel o su género, salvo que exista una justificación razonable para ello.

El matiz es importante, porque introduce un elemento que favorece la posición jurídica de los supuestos discriminados. Ya no se trata de ponderar el art. $22 \mathrm{CE}$ con el art. $14 \mathrm{CE}$; de lo que se trata es de ponderar una dimensión concreta del art. $22 \mathrm{CE}$ - el derecho a la autoorganización — con una dimensión

y julio de 2008), aludiendo a que las mujeres podían haber convocado otra reunión para conmemorar un alarde no tradicional, con mujeres. Al intentar irrumpir en el Alarde tradicional estaban afectando al derecho de reunión de éstos, siendo que el suyo no se ve afectado por la posibilidad de convocar otro Alarde.

Me parece importante traer este supuesto a colación, pese a que se trata de un conflicto con el derecho de reunión, no de asociación, porque es un buen ejemplo de cómo no se ha utilizado un concepto amplio de la posición de dominio. El Alarde tradicional es la fiesta del pueblo, está en una posición de dominio: un Alarde alternativo no es una respuesta proporcionada que compense la discriminación. Por último, una reflexión. Una miembro de la asociación de mujeres que denunció la discriminación criticó la sentencia del Tribunal Supremo afirmando que ésta significaba que "cualquier asociación pueda decir que el Alarde no puede tener negros o que no puede tener personas que no tengan ocho apellidos vascos». Si es esto así, que parece que sí, ¿es aceptable? Nunca se hizo con negros, se podría decir, es la tradición. Parece que la discriminación de las mujeres nos parezca a primera vista menos odiosa de lo que debería, a tenor de lo decidido por el Tribunal Supremo. 
concreta del art. $22 \mathrm{CE}$ - la dimensión inter privatos—, que pertenece también, según el TC, a su contenido esencial, reforzada con el principio de no discriminación del art. $14 \mathrm{CE}$. Ello no quiere decir que todos los supuestos en los que se ponderen ambos derechos deben resolverse tomando partido por los derechos de los socios - o potenciales socios- a no ser discriminados, pues ello dependerá de cada caso, como ocurre tantas veces en la jurisprudencia constitucional. Pero supone, sin duda, un elemento importante para presumir que dicha ponderación no debería resolverse a favor de la autonomía asociativa salvo que existan motivos poderosos para ello.

Hay que recordar que todavía estamos analizando una posible ponderación de derechos sin previa intervención legal, aspecto que contemplaremos en el siguiente epígrafe. Bien, pues en esta situación, que es la que a día de hoy tenemos en España, según lo mantenido hasta ahora en este artículo, no cabría en ningún caso una expulsión de una asociación porque se descubriera que el socio comparte alguno de los rasgos discriminatorios, siempre que dicho rasgo nada tenga que ver con los fines de la asociación. Es decir, ninguna asociación, aunque sólo sea una sociedad dedicada a compartir alguna afición sin posición de dominio o repercusiones sociales en su actividad, debería poder expulsar a un socio porque se descubriera su homosexualidad, o porque se descubriera que en lugar de blanco en realidad tiene $1 / 4$ de sangre negra. Este tipo de actitudes no pueden venir amparadas en la dimensión autoorganizativa del derecho de asociación, porque no pueden venir contempladas como causa de expulsión en los estatutos, pues ello los convertiría en contrarios a la Constitución, porque si no vienen contempladas en los Estatutos se trata de decisiones de los órganos de gobierno de la asociación que no respetan el proceso debido que ampara al socio, al ser arbitrarias. Por todo ello, no sólo vulneran el art. 14 CE sino también el art. 22 $\mathrm{CE}$, el derecho de asociación de esa persona.

Este caso es muy claro, al contrario que otros, que son más dudosos. Cuando hablemos de no admisión en lugar de expulsión, cuando haya una tradición secular detrás que respalde la utilización del rasgo sospechoso, cuando exista la posibilidad de que las personas excluidas formen otra asociación que pueda realizar los mismos fines, los tribunales deberán ponderar los derechos que se confrontan, e inclinarse por aquello que, caso a caso, sea más equilibrado. Algunos podrían pensar que lo ideal sería poder establecer, a raíz de la jurisprudencia, categorías más cerradas en las que supiéramos de antemano en qué supuestos prevalecería el derecho de asociación en su versión auto-organizativa y en qué supuestos no. Sin embargo, salvo en el capítulo de la expulsión antes citado, ello no es posible en el actual estado embrionario de la jurisprudencia. Lo que sí se puede afirmar es que, al contrario de lo que ha opinado gran parte de la doctrina, el derecho a la auto- 
organización de la asociación no siempre prevalecerá, y que la ponderación del mismo se realiza también con el derecho de asociación, en una de sus manifestaciones, y no sólo con el derecho a la no discriminación. Pero para concretar en qué supuestos las asociaciones podrán utilizar los rasgos sospechosos no podemos recurrir a categorías inducidas por lo realizado por la jurisprudencia constitucional en la ponderación de estos derechos. Como esta jurisprudencia no existe, esta concreción sólo puede llevarse a cabo a través de la ley.

\section{6. ÁMBITO DE ACTUACION DEL LEGISLADOR A LA HORA DE REGULAR LA NO DISCRIMINACIÓN COMO LÍMITE DE LA AUTONOMÍA ORGANIZATIVA}

Como vimos antes, según el TC, el principio de no discriminación reconocido en el art. $14 \mathrm{CE}$ puede aplicarse directamente a las relaciones entre particulares, es decir, no requiere de previa intervención legal. Sin embargo, la prohibición legal de discriminación (por ejemplo, art. 17 ET en el ámbito laboral) es un instrumento muy convincente a la hora de reforzar la posición jurídica de las personas que han sido discriminadas, pues concreta y refuerza la prohibición discriminatoria en un ámbito en el que la autonomía de la voluntad juega como límite al control constitucional de los actos sospechosos de discriminación.

En el ámbito de las asociaciones, la LODA no recoge la prohibición legal de discriminar. Lo que hace, en su art. 4.5, es prohibir a los poderes públicos que faciliten algún tipo de ayuda a las asociaciones que en su proceso de admisión o en su funcionamiento discriminen por razón de nacimiento, raza, sexo, religión, opinión o cualquier otra condición o circunstancia personal o social.

Se trata de un precepto discutible. En primer lugar, porque hace presuponer la posibilidad de que en los estatutos asociativos pudieran existir normas discriminatorias, en cuyo caso la única consecuencia jurídica que ello tendría sería la prohibición de recibir ayudas públicas. Pero como señalan GONZÁLEZ PÉREZ y FERNÁNDEZ FARRERES, algo así entraría en contradicción con el art. 2.4 de la LODA, que incluye entre los principios que informan la reglamentación del derecho de asociación que su organización y funcionamiento se llevará a cabo dentro el marco de la Constitución, de la LODA y del resto del ordenamiento jurídico, lo que excluye cláusulas de admisión o de funcionamiento basadas de forma arbitraria e irrazonable en rasgos discriminatorios ${ }^{30}$. Di-

30 FERNÁNDEZ FARRERES, G. y GONZÁLEZ PÉREZ, J.: Derecho de asociación (Comentarios a la Ley Orgánica 1/2002, de 22 de marzo), Civitas, op. cit., p. 172. 
gamos que el art. 4.5 de la LODA, en lugar de luchar contra la discriminación, la refuerza.

En segundo lugar, porque se refiere exclusivamente a los rasgos «sospechosos» recogidos en el art. $14 \mathrm{CE}$, obviando otros muchos recogidos en convenios internacionales de protección de derechos fundamentales ratificados por España ${ }^{31}$. Tampoco es necesario que se recojan todos y cada uno de los rasgos sospechosos frecuentemente utilizados en la doctrina y jurisprudencia nacional e internacional, más allá del género o la etnia, pero como mínimo se debería haber incluido los expresamente señalados en las Directivas comunitarias contra la discriminación — discapacidad, edad, orientación sexual— que no están en la lista de la Constitución ${ }^{32}$, pero sí en la legislación antidiscriminatoria comunitaria y española .

Por todo ello, en mi opinión, si tiene que haber una referencia legal respecto a la no discriminación, ésta debería consistir en una obligación directa de que las asociaciones no pudieran utilizar como causa de admisión o de expulsión alguno de los rasgos prohibidos en la Constitución ${ }^{33}$ y las Directivas comunitarias, siempre que la utilización de dichos rasgos se produzca de manera arbitraria, es decir, sin relación alguna con los fines políticos, sociales, religiosos, ideológicos de la sociedad.

La principal preocupación que suscita en gran parte de la doctrina un precepto de este tipo es que pudiera afectar al contenido esencial del derecho de asociación en su vertiente autoorganizativa. Ya hemos analizado anteriormente que se trata de un conflicto entre una dimensión de este derecho, la autoorganizativa, y otra dimensión, la inter privatos, que pertenece también a su conte-

31 El artículo 14 del Convenio Europeo de Derechos Humanos de 1950 recoge como rasgos sospechosos la raza, el sexo, el color, la lengua, la religión, las opiniones políticas u otras, el origen nacional o social, la pertenencia a una minoría nacional, la fortuna, el nacimiento o cualquier otra situación». El art. 21 de la Carta Europea de Derechos Fundamentales, que acaba de convertirse en Derecho comunitario vinculante con la entrada en vigor del Tratado de Lisboa, recoge los siguientes rasgos sospechosos: «sexo, raza, color, orígenes étnicos o sociales, características genéticas, lengua, religión o convicciones, opiniones políticas o de cualquier otro tipo, pertenencia a una minoría nacional, patrimonio, nacimiento, discapacidad, edad u orientación sexual».

32 Concretamente, en la Directiva 2000/78, del Consejo, de 27 de noviembre de 2000, y en la propuesta de Directiva de 2 de julio de 2008.

${ }^{33} \mathrm{Al}$ sexo, la raza, la religión, la opinión y el nacimiento, expresamente citados en el art. 14 CE, habría que añadir la discapacidad, por haber sido incorporada por la STC 269/1994 a este elenco, a través de la cláusula abierta del art. $14 \mathrm{CE}$ in fine. También incorporaría la orientación e identidad sexual, por cumplir con los parámetros que las jurisprudencias constitucionales parecen exigir para constituir un rasgo sospechoso (ver GIMÉNEZ GLUCK, D.: Juicio de igualdady Tribunal Constitucional, op. cit., pp. 230-236). 
nido esencial. Soy de la opinión de que una prohibición sin más podría dañar de tal manera el derecho a la autoorganización que pudiera afectar al contenido esencial de la libertad de asociación, pero que una redacción como la que se propone no incurriría en ello.

En primer lugar, porque las conductas que se restringen son sólo dos - la admisión y la expulsión-, precisamente aquellas donde el ciudadano individualmente considerado se juega en mayor medida su libertad de asociación en combinación con el derecho a no ser discriminado. El resto de actuaciones que componen lo que se denomina el funcionamiento de la asociación no se verían afectadas. En este sentido, este precepto sería bastante menos invasivo de la autonomía asociativa que el art. 2.5 LODA, que señala que la organización interna $\mathrm{y}$ «el funcionamiento» de las asociaciones deben ser democráticos, es decir, todo.

En segundo lugar, no se está prohibiendo sin más la utilización del rasgo sospechoso: a lo que se está obligando es a no incurrir en arbitrariedades con los socios o potenciales socios. Si una asociación tiene entre sus fines el culto a una virgen, tendrá pleno derecho a excluir a los no católicos de sus miembros. Si una asociación está formada por mujeres para la defensa de sus derechos, se podría interpretar que la no admisión —o expulsión — de hombres machistas no es una medida arbitraria al tener relación con los fines de la asociación. Si la asociación es de padres separados para la defensa de sus derechos sería perfectamente posible que excluyeran a mujeres separadas, el colectivo con el que se rivaliza. Lo único que se excluiría sería la no admisión o expulsión con base en el sexo, la raza, la religión, etc... sin base alguna, por mera aplicación de un prejuicio discriminatorio que se vería reforzado si se aceptaran este tipo de prácticas. Se está prohibiendo la discriminación arbitraria, porque la misma impide a determinados ciudadanos, sin ninguna razón, su derecho de asociación.

Otro aspecto relevante de estudio es la posible ubicación de este precepto. Una lectura atenta de la Constitución nos hace ver que el art. 22 establece como límite al derecho de asociación la prohibición de las asociaciones que persigan fines o utilicen medios tipificados como delitos. Por tanto, salvo las asociaciones secretas y las que tengan carácter paramilitar, es dudoso que se pueda prohibir una asociación si no persigue un fin o utiliza un medio tipificado como delito en el Código Penal ${ }^{34}$. ¿Significa ello que un precepto de las carac-

${ }^{34}$ Como dice LUCAS MURILLO, sólo podrá ser la autoridad judicial la que declare la disolución de una asociación, pero además, la motivación de las resoluciones de los órganos jurisdiccionales que dispongan la misma deberán basarse en alguna de las causas de ilicitud establecidas en la Constitución (MURILLO DE LA CUEVA, E. L.: El derecho de asociación, Tecnos, Madrid, 1996, p. 156). 
terísticas anteriormente definidas debería implementarse en el Código Penal? ¿Cómo podría hacerse algo así?

A la primera pregunta, la propia LODA responde negativamente prohibiendo las asociaciones con un funcionamiento no democrático, supuesto distinto de los establecidos por el art. $22 \mathrm{CE}$. Quizás lo que ocurre es que lo que señala el art. $22 \mathrm{CE}$ es exclusivamente qué fenómenos asociativos se dejan fuera de la esfera de protección del derecho fundamental ${ }^{35}$, sin que ello suponga necesariamente que cualquier otro tipo de asociación deba ser permitida por la ley, pese a que en su comportamiento no se respete los derechos de sus socios o lo establecido por la Constitución y la ley. En último término, los tribunales deberán valorar en cada caso la posible aplicación de estas cláusulas.

En cualquier caso, no hay duda alguna de que una regulación a través del Código Penal sería menos controvertida constitucionalmente. Es decir, se trataría de reconocer la discriminación arbitraria como un ilícito penal, a fin de declarar su ilegalidad. Algo de eso ya existe: el art. $515.5^{\circ}$ del Código Penal establece que son punibles las asociaciones ilícitas, teniendo tal consideración las que promuevan la discriminación, el odio o la violencia contra personas, grupos o asociaciones por razón de su ideología, religión o creencias, la pertenencia de sus miembros o de alguno de ellos a una etnia, raza o nación, su sexo, orientación sexual, situación familiar, enfermedad o minusvalía, o inciten a ello ${ }^{36}$.

Se considera ilícita la asociación que "promueva» la discriminación, el odio o la violencia, pero no aquella que utilice rasgos sospechosos, como la raza o el género, para discriminar de forma arbitraria en la admisión o expulsión de socios. Si quisiéramos incluir esta última categoría entre las asociaciones ilícitas, podríamos

${ }^{35}$ Como dice GARCÍA TORRES se trata de normas de garantía del derecho fundamental de asociación en cuanto determinan qué tipo de asociaciones no quedan amparadas por el art. $22 \mathrm{CE}$ (GARCÍA TORRES, J.: «Las asociaciones prohibidas por la Constitución» en Los derechos fundamentales y libertades públicas (I), volumen II, Ministerio de Justicia, Madrid, 1992, p. 1815).

36 Por tanto, será ilegal una asociación que promueva o incite a la discriminación: no se está diciendo que sería ilegal por cometer el delito de incitar a la discriminación, pues entonces entraría dentro del ámbito del art. 515,1 CP (son ilícitas las asociaciones que «tengan por objeto cometer algún delito»), en conexión con el art. $510 \mathrm{CP}$, que tipifica la provocación de la discriminación como delito, y el art. 515.5 sería superfluo. «Incitar o promover» no es lo mismo que "provocar». Lo que se señala es un delito de tipo asociativo específico. Por ello, según AGUIAR DE LUQUE se trata de un precepto de dudosa constitucionalidad (AGUIAR DE LUQUE, L.: "Derecho de asociación» en Enciclopedia Jurídica Básica, Vol. II, Civitas, Madrid, 1995, 2219). La misma opinión en VÍRGALA FORURIA, E.: «Las asociaciones inconstitucionales» en MORODO R. y DE VEGA P.: Estudios de Teoría del Estado y Derecho Constitucional en honor de Pablo Lucas Verdú, Tomo III, Servicio Publicaciones Facultad de Derecho, Universidad Complutense de Madrid, Madrid, 2001, 2010-2011. 
añadir al final del art. 515.5 CP algo así como: «(...) o la utilización expresa o implícita de dichos rasgos en la admisión o expulsión de la asociación, salvo que responda a una justificación objetiva y razonable relacionada con las finalidades de la misma». Así, la asociación que discriminara arbitrariamente en su proceso de selección o expulsión sería una asociación ilícita, y, por tanto, delictiva.

Puede que esta solución penal sea más acorde con la literalidad del art. 22 $\mathrm{CE}$, pero por desproporcionada ${ }^{37}$ resultaría inaplicable. Pese a no seguir la literalidad del precepto constitucional, prefiero la opción de una reforma matizada de la LODA, en la línea de lo que se está debatiendo para el futuro anteproyecto de ley de igualdad de trato, actualmente en fase de redacción.

\section{BIBLIOGRAFÍA}

AGUIAR DE LUQUE, L. y ELVIRA PERALES, A.: «Artículo 22. El derecho de asociación» en ALZAGA VILLAAMIL, O.: Comentarios a la Constitución Española de 1978, Título II, Edersa, Madrid, 1997.

—, «Derecho de asociación» en Enciclopedia Jurídica Básica, Vol. II, Civitas, Madrid, 1995.

BELUCHE RINCÓN I.: «La autonomía estatutaria y el principio democrático en la organización de las asociaciones» en ABRIL CAMPOY, J. M. y AMAT LLARI, M. E. (coords.): Homenaje al Profesor Lluis Puig i Ferriol, Tirant lo Blanch, Valencia, 2006.

BILBAO UBILLOS, J. M.: «Prohibición de discriminación y relaciones entre particulares» en Teoría y Realidad Constitucional, 18, 2006.

—, La eficacia de los derechos fundamentales frente a los particulares (análisis de la jurisprudencia del Tribunal Constitucional), CEPC, Madrid, 1997.

DÍEZ-PICAZO GIMÉNEZ, L. M.: Sistema de derechos fundamentales, Civitas, Madrid, 2003.

ELVIRA PERALES, A.: «A vueltas con el derecho de asociación (Comentario a las Sentencias 133/ y 135/2006, ambas de 27 de abril) en Revista Española de Derecho Constitucional, 83, Mayo-Agosto 2008.

—, «Asociaciones y democracia interna» en ARAGÓN REYES, M.; JIMÉNEZ CAMPO, J. y SOLOZÁBAL ECHAVARRÍA, J. J. (coords.): La democracia constitucional. Estudios en homenaje al Profesor Francisco Rubio Llorente, Congreso de los Diputados, Madrid, 2002.

FERNÁNDEZ FARRERES, G. y GONZÁLEZ PÉREZ V.: Derecho de asociación. Comentario a la Ley Orgánica 1/2002, de 22 de marzo, Civitas, Madrid, 2002.

37 Además de la disolución de la asociación, el art. 521 del Código Penal establece que si el reo de asociación ilícita fuera autoridad, agente de ésta o funcionario público, se le impondrá inhabilitación absoluta de diez a quince años. 
GALLARDO MOYA, V.: «Derecho de asociación y exigencia de democracia interna de los partidos políticos (Comentario a la STC 56/1995, de 6 de marzo)» en Derecho Privado y Constitución, 8, 1996, p. 245.

GARCÍA TORRES, J.: «Las asociaciones prohibidas por la Constitución» en Los derechos fundamentales y libertades públicas (I), volumen II, Ministerio de Justicia, Madrid, 1992.

GIMÉNEZ GLUCK, D.: Juicio de igualdad y Tribunal Constitucional, Ed. Bosch, Barcelona, 2004.

LÓPEZ AGUILAR, J. F.: Derechos fundamentales y libertad negocial (sobre el espacio constitucional para la autonomía de la voluntad entre particulares), Ministerio de Justicia, Madrid, 1990.

MARÍN LÓPEZ, J. J.: «La intervención judicial en los conflictos endoasociativos: el caso de la expulsión de los afiliados» en Poder Judicial, 14, 1989.

—, «Derecho fundamental de asociación: aplicación a las cooperativas. Expulsión de asociado; control sobre las causas de expulsión; ámbito de intervención judicial (Comentario a la Sentencia del Tribunal Constitucional 96/1994, de 21 de marzo)» en Cuadernos Civitas de Jurisprudencia Civil, 35, 1994.

MARTÍN HUERTAS, A.: El contenido esencial del derecho de asociación, Congreso de los Diputados, Madrid, 2009.

MURILLO DE LA CUEVA, E. L.: El derecho de asociación, Tecnos, Madrid, 1996.

PACE, A.: "Igualdad y libertad» en Revista Española de Derecho Constitucional, 64, Enero-Abril 2002.

PÉREZ ESCALONA, S.: La asociación y el Derecho de sociedades: una revisión en clave contractual, Civitas, Madrid, 2007.

- El derecho de asociación y las asociaciones en el sistema constitucional español, Thomson, Madrid, 2007.

QUESADA SÁNCHEZ, Antonio José: «Democracia interna y asociaciones: reflexiones desde una óptica civil» en Diario la Ley, n. 7062, 24 Nov. 2008.

RODRÍGUEZ-PIÑERO, M. y FERNÁNDEZ LÓPEZ, M. F.: Igualdad y discriminación, Tecnos, Madrid, 1986.

SALVADOR CODERCH, P. y FERRER I RIBA, J.: «Asociaciones, democracia y Drittwirkung» en Asociaciones, derechos fundamentales y autonomía privada, Civitas, Madrid, 1997.

VIDAL MARÍN, T.: «El derecho fundamental de asociación y el control judicial de la actividad interna de las asociaciones» en ESPÍN TEMPLADO, E. y DÍAZ REVORIO, F. J.: La Justicia Constitucional en el Estado democrático, Tirant lo Blanch, Valencia, 2000.

VÍRGALA FORURIA, E.: «Las asociaciones inconstitucionales» en MORODO, R. y DE VEGA, P.: Estudios de Teoría del Estado y Derecho Constitucional en honor de Pablo Lucas Verdú, Tomo III, Servicio Publicaciones Facultad de Derecho, Universidad Complutense de Madrid, Madrid, 2001. 
Title

ASSOCIATION, DISCRIMINATION AND THE CONSTITUTION: THE LINE BETWEEN FREEDOM OF ASSOCIATION AND THE RIGHTS OF MEMBERS - AND THOSE WHO WANT TO BE MEMBERS - TO NOT BE DISCRIMINATED AGAINST

\section{Summary}

1. INTRODUCTION: DEFINITION OF THE OBJECT OF ANALYSIS. 2. CONCEPT AND EXTENT OF THE RIGHT TO ASSOCIATION IN CONNECTION WITH INTERNAL SELFORGANIZATION. 3. LIMITS OF THE RIGHT TO SELF-ORGANIZATION: THE DEMOCRATIC PRINCIPLE AND THE INTER PRIVATOS DIMENSION. 4. CONCEPT, EXTENT AND LIMITS OF THE RIGHT TO NOT BE DISCRIMINATED AGAINST IN PRIVATE RELATIONS. 5. THE LINE BETWEEN RIGHT TO SELF-ORGANIZATION AND THE RIGHTS OF MEMBERS - AND THOSE WHO WANT TO BE MEMBERSTO NOT BE DISCRIMINATED AGAINST. 6. SCOPE OF ACTION OF LEGISLATIVE POWER TO REGULATE THE PRINCIPLE OF NON-DISCRIMINATION AS A LIMIT TO RIGHT TO SELF-ORGANIZATION OF THE ASSOCIATIONS.

\section{Resumen}

Este artículo tiene por objeto el análisis de la relación entre el derecho de los socios a su auto-organización interna, sin injerencias procedentes de los poderes públicos, y el derecho de estos mismos socios - y aspirantes a serlo_ - a no ser discriminados en su relación con la asociación. Así como el principio democrático ha sido aceptado como un límite legal frente al derecho a la auto-organización interna, los derechos de los socios - y aspirantes a serlo- en su relación inter privatos con la asociación forman también parte, según el TC, del contenido esencial del derecho de asociación y, por tanto, limitan la capacidad autoorganizativa de la asociación. Entre estos derechos se sitúan la imposibilidad de la no admisión o la expulsión de socios por causas arbitrarias, injustificadas, entre las que, en opinión del autor, se deben encuadrar aquellas que se basen en los rasgos especialmente odiosos que señala la Constitución, como la raza o el género, cuando dichos rasgos nada tengan que ver con la finalidad de la asociación. En todo caso, los Tribunales deberán hacer una ponderación, caso a caso, entre el art. 22 CE en su dimensión auto-organizativa y el art. $22 \mathrm{CE}$ en su dimensión inter privatos en coordinación con el art. $14 \mathrm{CE}$, sin 
que una posible futura previsión legal prohibiendo las prácticas discriminatorias pudieran tacharse de inconstitucional.

\begin{abstract}
This article analyses the relationship between the rights of the members of an association to self-organization without interferences from the State, and the rights of the members - and those who want to be members - to not be discriminated against in their connection to the association. As the democratic principle has been accepted as a legal limit to internal self-organization, the rights of the members and those who want to be members in their relationship inter privatos with the association are part of the essential content of the right to association, according to the Constitutional Court. Therefore, they limit the selforganization of the association. Among these rights we find the right to stop an arbitrary non admission and expulsion of members. The author thinks that members have the right to stop a non admission or expulsion based on race, gender or other grounds that are deemed as especially hateful by Constitution as part of their rights inter privatos, but only if the goal of the association doesn't justify the use of these grounds. In the end, the Courts might find a balance, case by case, between article $22 \mathrm{CE}$ (right to association) in their self-organizational dimension and art. $22 \mathrm{CE}$ (right to association) in their inter privatos dimension in connection with the article $14 \mathrm{CE}$ (right to equality). But if any law forbids the discrimination in the future, it will be constitutional.
\end{abstract}

Palabras clave

Derechos fundamentales, asociación, discriminación, igualdad, raza, género.

Key words

Fundamental rights, association, discrimination, equality, race, gender. 